\title{
Design of Collaborative Learning Education Model Based on Educational Data Interactive Information
}

\author{
Kaitao Gao \\ Distance Education College of Beijing Institute of Technology, Beijing, 100081, China
}

Keywords: Collaborative education, Educational model, Interactive information, Information technology.

\begin{abstract}
The rapid development and educational application of interactive whiteboard provide the conditions and opportunities for the realization of collaborative learning model. In order to attract more social forces to pay attention to and participate in the information literacy education of University, successfully constructed in line with actual situation based on Constructivism education theory as guidance, to cultivate students' creative thinking ability as the goal, to the library as the backbone and the main organizer, issued by the Ministry of Education mandatory document the College Library Work Committee for policy support, the librarians and teachers' cooperation as the starting point of the whole society to participate in the information literacy of diversified cooperative education model.
\end{abstract}

\section{Introduction}

With the rapid development of mobile Internet, support interactive learning tools is also undergoing new changes: from the traditional classroom teacher-student interaction and students collective face to face, to the remote interaction based on network technology, to the mobile Internet based on real-time personalized interaction between teachers and students. Interactive learning continues to improve our teaching methods, enhance our ability to use technology to carry out teaching. Nowadays, live broadcast based on smart phones, as a representative of learning and interactive tools in the mobile Internet era, can support viewers to interact with live viewers through strong interaction functions such as barrage or virtual props. Therefore, the interactive learning mode using mobile phone broadcast is conducive to creating an open and personalized interactive environment for teachers and students, and further promoting the development of interactive learning. But in the current teaching practice, many teachers still use interactive media teaching, only locate in the active classroom atmosphere, stimulate interest in learning, provide intuitive support and other superficial goals, while ignoring the use of interaction.

There are 3 forms of organization in depth learning and target learning: competitive organization, individual organizational structure and collaborative organizational structure. Studies have shown that collaborative learning organizational form can improve students' academic performance better than the other two organizational structures. Among them, the educational application and rapid development of interactive whiteboard provide the conditions and opportunities for the realization of collaborative learning model. Using interactive whiteboard, we can carry out various teaching modes, such as interactive generation, autonomous learning mode, collaborative learning model and so on. However, at present, little major leaders and teachers in China only regard interactive whiteboard as "blackboard substitute", only use simple functions such as searchlight, curtain and writing of interactive whiteboard, so as to realize the so-called "integration" model of information technology and curriculum. This paper explores how to use interactive whiteboard to develop collaborative learning. 


\section{Collaborative Learning}

\section{Definition of Collaborative Learning Concept}

Cooperative learning and cooperative learning are difficult to distinguish between two words in chinese. The traditional face-to-face cooperative learning came into being in the late 1960s, and gradually formed in the wave of teaching reform. Peng Shaodong believes that collaborative learning is equivalent to cooperative learning at the moment, and does not make a strict distinction. Until the end of the 1980s, computer supported collaborative learning (CSCL) emerged, and the two began to differentiate. The field of educational technology began to use collaborative learning, while the teaching field was still accustomed to using cooperative learning". In twenty-first Century, due to the emergence of blended collaborative learning (BCL), the two began to cross development. In this paper, the two do not distinguish, all use collaborative learning.

(1) target oriented. Any study aims at achieving a certain learning goal. For different collaborative learning goals, the corresponding collaborative learning strategies should be chosen.

(2) group work as learning form. The expression of collaborative learning emphasizes the study in groups or teams, and focuses on the cooperation, mutual assistance and interaction among peers.

(3) construct learning content with collaborative knowledge. Collaborative learning through division and cooperation, multiple learners use learning resources, actively communicate with each other, explore and solve problems mutually, form consensus, and construct knowledge together.

\section{The Theory of Collaborative Learning}

As a learning model or strategy, cooperative learning has a profound theoretical basis, and many learning theories support it more or less, but these theories are not contradictory, but complementary.

Humanistic psychology advocates "free learning", thinks learners have the ability to learn, and when learners participate in the whole process of learning, the learning effect is most obvious. In addition, the humanistic psychology group also believes that group learning and peer learning can make learners learn better. Rodgers, a representative of humanistic psychology, believes that peer teaching is an effective way to promote learning, and it is good for both students.

Social constructivism holds that knowledge is the process of individual initiative construction, and this construction process takes place in the social and cultural environment, and it is bound to constantly revise its own knowledge and ideas in the interaction with other people, so it is affected by certain historical and cultural factors. Therefore, learners' learning should not be isolated, but learning in a good social and cultural atmosphere. From the perspective of social constructivism, the core of collaborative learning lies in the interaction with external environment, such as group members. Multiple learners can become groups, to some extent, they can be regarded as learning communities.

Population dynamics is the science of exploring the relationship between population structure and population. Group dynamics holds that as a member of a society, it is interdependent with some other members' behavior. Among them, group cohesion is one of the bases of group existence. The significance of group cohesion lies in the formation of a group by sharing common goals, interests and mutual cooperation; through group activities, individuals not only acquire knowledge and ability, but also pursue interpersonal and respected needs. See from the perspective of cooperative learning group dynamics theory, is the core of team cohesion, team members that encourage each other and help each other, not only to achieve the desired goals, more important is the emotional enhancement.

\section{Basic Elements of Collaborative Learning}

Cooperative learning and cooperative learning are difficult to distinguish between two words in 
chinese. The traditional face-to-face cooperative learning came into being in the late 1960s, and gradually formed in the wave of teaching reform. Peng Shaodong believes that collaborative learning is equivalent to cooperative learning at the moment, and does not make a strict distinction. Until the end of the 1980s, computer supported collaborative learning (CSCL) emerged, and the two began to differentiate. The field of educational technology began to use collaborative learning, while the teaching field was still accustomed to using cooperative learning". In twenty-first Century, due to the emergence of blended collaborative learning (BCL), the two began to cross development. In this paper, the two do not distinguish, all use collaborative learning.

(1) target oriented. Any study aims at achieving a certain learning goal. For different collaborative learning goals, the corresponding collaborative learning strategies should be chosen.

(2) group work as learning form. The expression of collaborative learning emphasizes the study in groups or teams, and focuses on the cooperation, mutual assistance and interaction among peers.

(3) construct learning content with collaborative knowledge. Collaborative learning through division and cooperation, multiple learners use learning resources, actively communicate with each other, explore and solve problems mutually, form consensus, and construct knowledge together.

\section{The Theory of Collaborative Learning}

As a learning model or strategy, cooperative learning has a profound theoretical basis, and many learning theories support it more or less, but these theories are not contradictory, but complementary.

Humanistic psychology advocates "free learning", thinks learners have the ability to learn, and when learners participate in the whole process of learning, the learning effect is most obvious. In addition, the humanistic psychology group also believes that group learning and peer learning can make learners learn better. Rodgers, a representative of humanistic psychology, believes that peer teaching is an effective way to promote learning, and it is good for both students.

Social constructivism holds that knowledge is the process of individual initiative construction, and this construction process takes place in the social and cultural environment, and it is bound to constantly revise its own knowledge and ideas in the interaction with other people, so it is affected by certain historical and cultural factors. Therefore, learners' learning should not be isolated, but learning in a good social and cultural atmosphere. From the perspective of social constructivism, the core of collaborative learning lies in the interaction with external environment, such as group members. Multiple learners can become groups, to some extent, they can be regarded as learning communities.

Population dynamics is the science of exploring the relationship between population structure and population. Group dynamics holds that as a member of a society, it is interdependent with some other members' behavior. Among them, group cohesion is one of the bases of group existence. The significance of group cohesion lies in the formation of a group by sharing common goals, interests and mutual cooperation; through group activities, individuals not only acquire knowledge and ability, but also pursue interpersonal and respected needs. See from the perspective of cooperative learning group dynamics theory, is the core of team cohesion, team members that encourage each other and help each other, not only to achieve the desired goals, more important is the emotional enhancement.

\section{Basic Elements of Collaborative Learning}

\section{Construction Methods}

The activity model is based on activity theory, and the basic unit in activity theory is activity. The activity system consists of 3 core components (subject, object and community) and 3 minor components (tools, rules and division of labor). The main relationship is shown in figure 1. 


\section{Basic Teaching Process}

(1) create situations and ask questions. Teachers use the teaching software and resource library in the whiteboard to create a certain learning situation and atmosphere, and stimulate students' interest in learning. Whiteboard pen convenient makes the teacher to the rostrum, better words and deeds. The teacher releases the study task through the white board or puts forward a question, and uses the magnifying glass and the searchlight of the white board to emphasize the function, so as to inspire the students to think.

Teachers should pay special attention to the design of problems. Try to design controversial, answer is not unique or no fixed answer and other structural problems, is conducive to stimulate the enthusiasm of students to explore and knowledge transfer. Teachers should also consider how to deal with the students may ask questions, teaching design for these problems.

(2) group cooperation, explore new knowledge. The teacher determines the basic structure of the group according to the specific learning tasks. Students may lack collaborative skills when they start collaborative learning. Therefore, teachers should first design skills and methods of collaborative learning. Students use the resource pool and Internet provided by teachers, and actively think about problems and seek answers through teamwork and partnership. In this process, students should learn to listen to the members of the group to talk, learn how to ask questions and express their views and opinions accurately, and encourage other members of the group to participate actively.

In the process of student group learning, teachers need to observe the students' learning process, and guide students to conduct more in-depth inquiry through the network. In addition, teachers can timely display relevant information through electronic whiteboard, in order to better help students carry out effective inquiry. Electronic whiteboard is convenient and flexible, so that teachers can be released from the courseware and become the regulator of the classroom.

(3) reporting results, feedback evaluation. The students gradually solved the problems raised by teachers through group discussion and independent thinking. Each team sends a representative to report the results of the group. In the process of reporting communication, students can use the white board notes, drawing, lists and blackboard writing functions, accurate expression of their views, the audience's interest also greatly improved. In the process of reporting, the group members can supplement, other groups can query and ask questions, promote the collision of various views, thus promoting the meaning construction of knowledge. After the group report, the teacher can write all kinds of questions and key points on the whiteboard and save them, so that they can organize and reflect after class. At the same time, teachers can save students' learning achievements, help students to manage knowledge and evaluate the process of students.

After students have mastered the methods of solving problems, teachers can design appropriate exercises for students to consolidate and promote the transfer of knowledge in time. According to the students' practice, the teacher will focus on the comments, comments on the Internet or use the electronic whiteboard to further guide the students.

\section{Conclusion}

Collaborative learning has become a very popular teaching mode. The information technology environment, especially the development of the Internet, provides a good condition for collaborative learning. Compared with traditional teaching, collaborative learning supported by information technology can provide rich context, integrate a large number of teaching resources, and provide learning tools for group activities. Among them, the unique function of interactive whiteboard can build learning situation, clearly show learning tasks; students through interactive whiteboard provides learning platform, collaborative learning, complete knowledge inquiry. The teaching and research of collaborative learning based on interactive whiteboard need more scholars and teachers to pay attention to and explore. 


\section{References}

[1] Weisen Pan, Shizhan Chen, Zhiyong Feng. Automatic Clustering of Social Tag using Community Detection. Applied Mathematics \& Information Sciences, 2013, 7(2): 675-681.

[2] Yingyue Zhang, Qi Li, William J. Welsh, Prabhas V. Moghe, and Kathryn E. Uhrich, Micellar and Structural Stability of Nanoscale Amphiphilic Polymers: Implications for Anti-atherosclerotic Bioactivity, Biomaterials, 2016, 84, 230-240.

[3] Jennifer W. Chan, Yingyue Zhang, and Kathryn E. Uhrich, Amphiphilic Macromolecule Self-Assembled Monolayers Suppress Smooth Muscle Cell Proliferation, Bioconjugate Chemistry, 2015, 26(7), 1359-1369.

[4] Dalia S. Abdelhamid, Yingyue Zhang, Daniel R. Lewis, Prabhas V. Moghe, William J. Welsh, and Kathryn E. Uhrich, Tartaric Acid-based Amphiphilic Macromolecules with Ether Linkages Exhibit Enhanced Repression of Oxidized Low Density Lipoprotein Uptake, Biomaterials, 2015, 53, 32-39.

[5] Yingyue Zhang, Ammar Algburi, Ning Wang, Vladyslav Kholodovych, Drym O. Oh, Michael Chikindas, and Kathryn E. Uhrich, Self-assembled Cationic Amphiphiles as Antimicrobial Peptides Mimics: Role of Hydrophobicity, Linkage Type, and Assembly State, Nanomedicine: Nanotechnology, Biology and Medicine, 2017, 13(2), 343-352. 